\title{
Early Temperamental Traits in an Octopus (Octopus bimaculoides)
}

\author{
David L. Sinn and Nancy A. Perrin \\ Portland State University
}

\author{
Jennifer A. Mather \\ University of Lethbridge
}

\author{
Roland C. Anderson \\ The Seattle Aquarium
}

\begin{abstract}
During their 3rd week of life, 73 Octopus bimaculoides were observed to test whether discrete behaviors could be grouped reliably to reflect dimensions of temperament. Frequencies of behaviors during Week 3 were subjected to principal-components analysis (PCA), resulting in 4 components (active engagement, arousaVreadiness, aggression, and avoidance/disinterest) that explain 53\% of the variance. Levels of temperamental traits were then evaluated for 37 octopuses using composite scores at 3 time points across the first 9 weeks of life. Profile analysis revealed significant change for the testing group as a whole in trait expression levels from Week 3 to Week 6. Results also suggest a significant effect of relatedness on developing temperamental profiles of octopuses. Discussion focuses on how results apply to the life history of $O$. bimaculoides and what temperament can reveal about adaptive individuality in a protostome.
\end{abstract}

Individual differences in the behavioral tendencies of young organisms can be described as differential expression of temperamental traits. By definition, these traits are behavioral styles (as opposed to discrete acts) that appear early in life, are partly based on innate biological processes, and are the precursor to the adult personality (Rothbart, Ahadi, \& Evans, 2000). Temperamental features that are present from birth are shaped and modified throughout early development by interaction with the individual's environment (Braungart, Plomin, DeFries, \& Fulker, 1992; Clarke, 1993). Thus, initial temperamental tendencies have repercussions for both early survival and later adult behavioral expression (Clarke \& Boinski, 1995). Although there is debate as to the exact proximate causes of these differences in humans (McGue \& Bouchard, 1998; Plomin, 2000; Turkheimer, 1998), there is general

David L. Sinn, Department of Biology, Portland State University; Nancy A. Perrin, Department of Psychology and Systems Science Doctorate Program, Portland State University; Jennifer A. Mather, Department of Psychology, University of Lethbridge, Lethbridge, Alberta, Canada; Roland C. Anderson, The Seattie Aquarium, Seattle, Washington.

We are grateful to Samuel Gosling and Jean Boal for helpful discussions on this project. Peter Edmunds and Rebecca Habeeb provided constructive criticism on early drafts of this article. David L. Sinn thanks Leonard Simpson for laboratory space and financial support, Carrie Furrer for assistance with statistics, Marwan Adjaj for help with data collection, Shane Hockett and Judith Briner for assistance with octopus maintenance, Chuck Winkler for collection of octopuses, and the American Malacological Society and the Hawaiian Malacological Society for partial funding of this project. This work was conducted by David L. Sinn as partial fulfillment of a master's degree in biology at Portland State University.

Correspondence concerning this article should be addressed to David L. Sinn, who is now at the University of Tasmania, School of Aquaculture, Locked Bag 1-370, Launceston, Tasmania 7250, Australia. Electronic mail may be sent to dsinn@utas.edu.au. agreement that the temperamental profile of an organism is the result of biological factors (primarily genes), developmental context, and the interaction (or covariance) between these two (Goldsmith et al., 1987; Kagan \& Snidman, 1991; McGue \& Bouchard, 1998).

Although temperament as an explanation for human behavioral tendencies has been studied for at least 2,500 years (for a review, see Merenda, 1999), comparative animal studies within the past 25 years have begun to map the occurrence of similarly occurring psychological traits across a wider range of vertebrate taxa (primates: Stevenson-Hinde, Stillwell-Bames, \& Zunz, 1980a, 1980b; Suomi, Novak, \& Well, 1996; fishes: Francis, 1990; Wilson, Coleman, Clark, \& Biederman, 1993; pigs: Forkman, Furuhaug, \& Jensen, 1995; hyenas: Gosling, 1998; for a more comprehensive review, see Gosling, 2001). Such comparative studies have become more common as researchers have begun to realize the merit of animal models for understanding ecological and evolutionary (i.e., selecive adaptations) aspects of temperament and personality (Depue, 1995; Suomi, 1987). The results obtained from these wider ranging comparative studies can also give us valuable reference points for evaluating the development of cognitive processes for many taxa (including humans) along evolutionary time scales (Gosling, 2001).

How is the early individuality of organisms, which is expressed through their temperamental tendencies, important in understanding nonhuman animal behavior? Unique expression levels of temperamental traits can provide behavioral material for natural selection (Clarke \& Boinski, 1995) by conferring differential goodness-of-fit profiles to young organisms in reference to environmental conditions that they encounter (Talwar, Nitz, Lerner, \& Lerner, 1991). Variability in early temperamental traits among individuals may also ensure a population's survival in a highly variable, unpredictable, or changing environment (Katano, 1987; Slater, 1981). Under highly unpredictable and fluctuating condi- 
tions, genetic variability around behavioral traits would be conserved through stabilizing selection (Plomin, 1981), and parents could "hedge their bets" by producing multiple offspring with differing levels of temperamental trait expression. Maynard-Smith and Harper (1988) have illustrated three models in which stabilizing selection could maintain the phenotypic variability seen in aggressive traits, using songbirds as examples. Organism individuality could also be important in predator-prey interactions because an individualized prey item would continually provide a protean search image for predators (Sterrer, 1992). Instead of viewing individual behavioral variation in their subjects as evolutionary "noise," researchers have now begun to examine the evolutionary and ecological implications of consistent individual differences in behavioral styles (Armitage, 1986; Reale, Gallant, LeBlanc, \& Festa-Bianchet, 2000; Wilson et al., 1993).

\section{Methods for Studying Temperamental Trait Development}

There are a number of methods that can be used to test for temperamental trait features in both human and nonhuman animals. One method is purely exploratory and uses observational data, preferably from several tests, to derive a number of temperament dimensions that are thought to reflect underlying processes affecting discrete behaviors (e.g., Cattell \& Peterson, 1959; Stevenson-Hinde et al., 1980a, 1980b; Thomas \& Chess, 1977). It is worth noting that an exploratory method using three different behavioral tests was the method chosen here. Another method is similar to the first in that it is exploratory but uses human response data acquired through questionnaires to describe subjects' behaviors (e.g., Gosling, 1998). Questions are normally selected by the researcher to "pick out" certain temperament dimensions and generally are answered by more than one observer. Yet a third method for description of temperamental trait features is to hypothesize that a particular type of temperament already exists for the subject organism (e.g., Fox \& Henderson, 1999; Maestripieri, 2000; Wilson et al., 1993). Behavioral tests are then performed to assess whether a priori classifications of "type" are predictive of later behavioral outcomes. For example, Wilson et al. (1993) classified sunfishes as either shy or bold on the basis of individual tendencies to approach a novel stimulus (an unbaited trap). Additional tests then were performed to assess whether these classifications could be used to predict behavioral responses in different scenarios. If one of the first two exploratory methods is chosen, then the behavioral dimensions that arise from their analyses should be assessed for reliability (the third method, although making theoretical assumptions regarding presence or absence of traits, is itself a test of the reliability of predictions). By reliability, we mean here that temperamental traits should not be ephemeral in nature but should be strong indicators of underlying psychological processes. Because an exploratory model was used here, we initially asked two questions: Do octopuses display temperamental traits? If so, are the trait dimensions reliable assessments of enduring behavioral styles?

A common feature of human temperament theory has been the emphasis on the continuity of temperamental characteristics throughout an individual's life. Traits falling under the rubric of temperament are expected to be more stable or continuous relative to other personality variables (A. Buss, 1989; Strelau, 1989). Relative is stressed here because change is an essential feature of development, and most researchers report some degree of both stability and change in their results (e.g., Carnicero, Perez-Lopez, Salinas, \& Martinez-Fuentes, 2000; Stevenson-Hinde et al., 1980a, 1980b; Sunmi et al., 1996). Indeed, developmental studies of temperament present a paradox because change is an essential aspect of any developmental function, and yet some element of stability or continuity is also necessary for the maintenance of individual distinctiveness (Sackett, Sameroff, Cairns, \& Suomi, 1981). Thus, some researchers have interpreted findings of low stability as indicating problems in the concept or measurement of temperament (Hubert, Wachs, Peters-Martin, \& Gandour, 1982), whereas others have suggested that lack of stability reflects developmental changes in the expression of temperament itself (Riese, 1987). Simply put, consistency in developmental features or attributes is not easily definable and is highly complex. Caspi (1998) described five different kinds of stability that can be classified within two major types of continuity: homotypic and heterotypic (Kagan, 1969). The first type of continuity, homotypic, refers to the stability of similar behaviors or phenotypic attributes over time. For example, the same level of shy-bold tendencies to novelty within individuals or a group observed in infancy is expressed in later childhood. In contrast, heterotypic continuity refers to the continuity of a genotype or underlying trait despite changes in its phenotypic expression. Therefore, heterotypic continuity allows for differing levels of response along temperamental trait dimensions even though the underlying dimension itself influencing a response does not change. Considering these features of temperament trait development then, we asked a third question regarding octopus temperament: If octopuses do indeed display temperamental features throughout their early life, how might we characterize temperamental trait continuity and/or change through time?

\section{Using Octopuses as Models for Psychological Trait Testing}

The divergence of the protostome and deuterostome lineages (Wray, Levinton, \& Shapiro, 1996) can provide a useful reference point for evolutionary psychologists when making comparative assessments. Understanding the individuality of representative taxa from both major lineages can provide useful information regarding convergent and divergent processes associated with the evolutionary development of temperamental traits. Currently, there is a paucity of knowledge of individuality in invertebrates compared with that in the vertebrate deuterostomes, despite a relatively larger number of species and a high degree of behavioral diversity in the former (Barnes, 1987). Several arthropod studies (bees: Pflumm \& Wilhelm, 1982; ants: Bonavita-Cougourdan \& Morel, 1988; Retana \& Cerda, 1991) and one octopus study (Mather \& Anderson, 1993) have begun to delineate possible trait dimensions of individuality in invertebrates. Mather and Anderson (1993) provided the first psychological trait testing in the octopuses and outlined three broad personality traits in adult $O$. rubescens: activity, reactivity, and avoidance. In their study, Mather and Anderson observed sexually mature $O$. rubescens of unknown age in behavioral tests for 2 weeks and obtained results using a single analysis of summed frequencies of behaviors. In the current study, we attempted to further understand the individuality of these invertebrates by documenting temperamental features in an octo- 
pus. We intentionally chose to use the construct descriptor temperament in our study as opposed to personality. Although there is confusion over this distinction in both human and nonhuman animal literature (Gosling, 2001), our use of the term temperament was based on our observations of octopus behaviors that occurred early in their life. Personality measures, on the other hand, are normally used to describe later adult behavioral styles, which have been modified through learning (Mather \& Anderson, 1993).

O. bimaculoides (Pickford \& McConnaughy, 1949) was chosen as our subject organism because it can be reared in the laboratory from birth, with the young immediately adopting a benthic lifestyle after hatching (Forsythe \& Hanlon, 1988b). This is in comparison with small-egged Octopus species (spp.), which are significantly more difficult to rear from birth in laboratory settings because of their planktonic young (Boyle, 1987). Currently, most observations of young $O$. bimaculoides have come from laboratory studies (Forsythe \& Hanlon, 1988a; Sinn, 2000); only one study has reported limited in situ observations (Lang, 1997). Eggs are normally 3 to $4 \mathrm{~mm}$ in length, teardrop-shaped, and laid in groups of 150 to 500 that are then brooded by the females until hatching (Forsythe \& Hanlon, 1988a; Sinn, 2000). At hatching, the young octopuses are thought to disperse by crawling or swimming (Lang, 1997). O. bimaculoides are found from central California to mid Baja, Mexico, where they inhabit rocky reefs, kelp forests, and mudflats (Lang, 1997). Little is known concerning the juvenile life history of this or any other Octopus spp. because of the difficulty of observing young in the wild (for an exception, however, see Ambrose, 1988).

In summary, the aims of this study were as follows: (a) to document whether early behaviors in a protostome, $O$. bimaculoides, could be factored reliably into categories reflecting dimensions of temperament, (b) to assess whether early temperamental development in an invertebrate could be described according to vertebrate temperamental trait theory (i.e., developmental continuity and change), and (c) to assess the possible effects of relatedness on octopus temperamental trait development. The last aim of our study is consistent with temperamental trait theory that considers temperamental trait levels to be influenced by biological, or innate, components (Goldsmith et al., 1987). We end by discussing possible correlates of temperament with regard to the life history of $O$. bimaculoides and the relevance of using protostome representatives as comparative data points for vertebrate psychological processes.

\section{Method}

\section{Subjects}

Female Octopus bimaculoides $(n=8)$ with eggs were collected in the spring of 1999 from the wild in the Long Beach, California, area, shipped to Portland, Oregon, and maintained separately in holding tubs (76 L; $1.0 \times 0.3 \times 0.3 \mathrm{~m}$ ) until eggs were hatched. Holding tubs were maintained as part of a single in-line closed system $(3,028.33 \mathrm{~L})$ and were filled with artificial seawater (Instant Ocean brand mixed with deionized water) that was maintained at $18^{\circ} \mathrm{C}$ with salinities varying between 34 and $36 \mathrm{ppt}$. An in-line chiller tank with a $2,839 \mathrm{~L} / \mathrm{hr}$ pump was used to maintain temperature and water circulation. Individual holding tubs contained crushed oyster shell substrate, plastic sea grass blades, and other shelter (i.e., clay pots, small pieces of PVC pipe, and rocks). The system received overhead fluorescent lighting in addition to natural, indirect sunlight from large adjacent windows. The day-night cycle of the fluorescent lights was kept approximately the same as the day length of Portland, $\mathrm{OR}$, during all phases of experimentation. Because females were wildcaught, the father(s) of each individual egg/juvenile octopus was unknown. Multiple male $O$. bimaculoides are known to mate with the same female in the lab (Forsythe \& Hanlon, 1988b), and it is possible that more than two parental genotypes contributed to the genotype of individual octopuses in this study.

Because of their small size ( $<6 \mathrm{~mm}$ mantle length) and high mortality, juvenile octopuses were not tested until 14 days of age. At 14 days post-hatching, octopuses were removed from the holding tubs, weighed and measured, and housed separately in testing containers, thus allowing for identification by individual and by brood. The mean wet weight and mantle length for octopuses $(n=62)$ at 14 days old was $1.1 \mathrm{~g}(S D=0.45)$ and $6.5 \mathrm{~mm}(S D=0.90)$, respectively. Once placed individually into testing containers, octopuses were not moved for the remainder of the study. Testing containers were brown plastic cylindrical plant potholders approximately $10 \mathrm{~cm}$ in diameter and $14 \mathrm{~cm}$ deep. Containers were opaque on all sides and had opaque lids, which were removed to permit access to octopuses during testing. The last $12 \mathrm{~mm}$ of a polystyrene $13-\times 100-\mathrm{mm}$ culture tube was provided as a den for the hatchlings, with the top third of the tube clear to aid observation and the rest painted with black epoxy paint. Test containers were floated in 662-L water tables separate from the holding tubs. Water depth in testing containers was maintained at $10 \mathrm{~cm}$, and containers were continuously illuminated with indirect red light ( $25 \mathrm{~W}$ ) to allow for accurate visual observation during nighttime hours.

Before octopuses were 14 days old, they were fed a variety of foods including littorinid snails, mysid shrimp, limpets, amphipods, mole crabs, and appropriately sized (crab carapace width less than one half the mantle length of the octopus) live shore crabs. After Day 14, octopuses were not fed on testing days except during the last phase of experimentation; on days when testing did not occur, octopuses were presented with food items (live shore crabs, mysid shrimp, and littorinid snails) ad libitum. Human interaction with experimental octopuses was minimized during testing. However, interaction with test octopuses outside of testing situations was inevitable because containers were cleaned and octopuses were fed during nontesting periods.

Additional developmental histories of octopuses before Day 14 and during testing were as follows. After hatching, some nontested octopuses were removed from holding tubs to minimize densities of octopuses in these tubs. This resulted in the numbers of octopuses in the holding tubs before Day 14 to range from 27 to 45 , which are most likely exaggerated densities compared with natural conditions. Holding tub availability, hatchling die-off, and the need for identifiable testing animals were the necessary parameters in the decision to maintain these densities in holding tubs. Previous to 14 days of life, octopuses interacted with siblings only. After Day 14, all tested octopuses were isolated, as mentioned previously. Previous to Day 14, holding tubs were checked at least once daily to remove waste material, and no major differences in degree or type of interactions were noted between broods. Octopuses were not weighed or measured during testing to minimize contact. At the end of the testing period, octopuses were maintained until their death, which occurred before sexual maturity at approximately 5 months of age. Preliminary dissections of young animals were not conclusive regarding sex, so sex is not reported here.

\section{Test Procedure}

Octopuses were observed in a three-part testing series on each testing day. Tests began within $30 \mathrm{~min}$ of sunset, because preliminary observations indicated octopuses were crepuscular in activity. All direct observations of octopus behavior were performed by one person (David L. Sinn). Objective recordings of behavior from more than one observer are ideal (Feaver, Mendl, \& Bateson, 1986), but single observer results are common in 
studies of this type (e.g., wolves, MacDonald, 1983; octopuses, Mather \& Anderson, 1993; fishes, Budaev, 1997; primates, Maestripieri, 2000).

Observations were recorded by noting the occurrence of a behavior verbally into a microcassette recorder. At the end of each testing night. all results were transcribed from this voice tape into a computer. Although octopuses across known broods were tracked individually throughout the study period, analyses were not run until after all data were collected. Because of this, results of types of temperament dimensions as well as the discrete behaviors that would consequently load on each dimension were unknown at the time observations were made. This was done to minimize the possibility that an unconscious bias on the part of the observer would influence results. Testing methods were similar to those used by Mather and Anderson (1993) and were designed to represent naturalistic circumstances. The first test, termed alert, consisted of the experimenter lifting the opaque lid to the testing compartment and leaning over the top of the container. Octopus behaviors were recorded at the start of visual contact for $30 \mathrm{~s}$. The second test, termed threat, occurred directly after alert, and consisted of the experimenter touching the octopus with a $4-\mathrm{mm}$ diameter test-tube brush. Behaviors were recorded for $30 \mathrm{~s}$ beginning with the touch of the test-tube brush. The third test, feeding, took place 30 to $60 \mathrm{~min}$ after the threat test. Feeding was a live food presentation (live shore crabs), and behaviors in this last test were recorded for $10 \mathrm{~min}$ or until capture of the crab. Behaviors in feeding tests were recorded beginning with crab placement in the testing container.

Octopuses received the three-part testing series twice weekly during their 3rd (Days 16 and 19), 6th (Days 37 and 40), and 9th (Days 58 and 61) week of life. A total of 730 . bimaculoides were tested during the $3 \mathrm{rd}$ week of life, 37 were tested during the 6th week of life, and 37 were tested during the 9 th week of life. The atrition of octopuses was due to die-off or escape of those that then could not be positively identified. Data from the two testing periods in a given week were combined to create Week 3 , Week 6 , and Week 9 frequency scores for each behavior. A given behavior was recorded as occurring more than once within a test only if there was at least a 5-s break between instances of that behavior. This 5-s rule was imposed before experimentation.

\section{Data Analyses: Aim 1}

PCA and reliability and stability measurements on PCA data were used to address the first aim of our study: Can early behaviors in an octopus be reliably factored into categories reflecting dimensions of temperament?

$P C A$. Results obtained during the 3rd week of testing only were used to define possible temperamental trait dimensions. Temperamental traits normally are used to describe human infants less than 2 years old (Rothbart, 1986; Thomas \& Chess, 1977), and 1 week in an octopus's lifespan (assuming a lifespan of 18 months, likely for $O$. bimaculoides; Forsythe \& Hanlon, 1988a) would correspond roughly to 1 year in a human (assuming a 72-year lifespan). Furthermore, within this short lifespan, octopus development (physical, physiological, and behavioral) is rapid. The 3rd week was our earliest time point, and a week was the time span that was chosen to best represent the rapid behavioral development in our octopuses while not obscuring developmental processes.

We observed 19 behaviors during the 3rd week of testing, and 15 were chosen for analysis (Table 1) because they met the criteria of contributing at least $5 \%$ of the total behavioral repertoire observed during Week 3 testing. The summed frequencies of these 15 behaviors were then subjected to explonatory factor analysis (PCA model; Tabachnick \& Fidell, 1996) with direct oblimin rotation using SPSS for Windows (1997; $n=73$ ). Oblique rotation was chosen on a priori grounds that temperamental dimensions were most likely related, and not orthogonal (or uncorrelated) to one another. Orthogonal rotation was performed as well, and the results matched those obtained by oblique rotation. Because this was an explor-

Table 1

Definitions and Frequencies of 15 Behaviors Recorded for Octopus bimaculoides $(n=73)$ in Tests During Their First 9 Weeks of Life

\begin{tabular}{|c|c|c|c|}
\hline Behavior & $M$ & $S D$ & Operational definition \\
\hline Shrink & 1.55 & 0.85 & $\begin{array}{l}\text { A specific type of posture change: The arms and lower part of the body remained stationary while } \\
\text { the head and mantle increased the distance from the stimulus. }\end{array}$ \\
\hline Crawl & 2.79 & 2.97 & $\begin{array}{l}\text { Octopus moved along the bottom or side of the testing compartment using the arms as its means } \\
\text { of locomotion. }\end{array}$ \\
\hline Head movement & 0.66 & 0.90 & $\begin{array}{l}\text { Octopus made vertical (up and down), horizontal (side to side), or vertical/horizontal } \\
\text { (combination) movement of the head only. }\end{array}$ \\
\hline Touch stimulus ${ }^{\mathrm{a}}$ & 0.84 & 1.07 & Octopus initiated contact with the stimulus with one arm only. \\
\hline Pupil change & 0.89 & 0.89 & Octopus's pupils were enlarged. \\
\hline Papillae change & 0.25 & 0.79 & Octopus raised skin surface in papillae. \\
\hline Posture change & 1.34 & 1.52 & $\begin{array}{l}\text { Octopus's head and body changed position while maintaining a fixed point in space; this behavior } \\
\text { was not directional in regard to the stimulus. }\end{array}$ \\
\hline Color change & 2.38 & 2.15 & Octopus's overall skin color pattern was changed. \\
\hline Alert posture & 0.18 & 0.42 & $\begin{array}{l}\text { Octopus raised eyes and the mantle was held at a } 45^{\circ} \text { angle downward from vertical. The body } \\
\text { was held fixed, and the arms were tucked close to the body and used to raise the head/eyes } \\
\text { further in the vertical plane. }\end{array}$ \\
\hline Grab stimulus ${ }^{\mathrm{a}}$ & 0.79 & 0.71 & Octopus used more than one arm to contact the stimulus. \\
\hline Pull stimulus ${ }^{b}$ & 0.26 & 0.53 & $\begin{array}{l}\text { Octopus, after touching or grabbing, maintained hold with suckers and attempted to shorten } \\
\operatorname{arm}(\mathrm{s}) \text {. }\end{array}$ \\
\hline
\end{tabular}

Note. Means and standard deviations are given for behaviors observed in Week 3 testing only because it is these data that contributed to the principal-components analysis and resulting temperamental dimensions. Operational definitions were held constant throughout the testing period. All behaviors were displayed at all three time points and in all of the three test situations (alert, threat, or feeding) unless otherwise noted.

Occurred only during threat and feeding. 'Occurred in threat test only. 
atory factor analysis, no a priori assumptions were made regarding the number of components to retain. A decision regarding the number of components was based on the following criteria: (a) a scree test (Cattell, 1966), (b) eigenvalues $>1$ rule (Kim \& Mueller, 1978), (c) a parallel analysis (Montanelli \& Humphreys, 1976), and (d) interpretability of the factors themselves (Zwick \& Velicer, 1986). For interpretation, behaviors with loadings of at least \pm .4 were considered to contribute to the meaning of a component. Acceptable levels of loadings can be as low as \pm .32 in some cases (Tabachnick \& Fidell, 1996).

Reliability and stability measurements. A number of methods were used to assess the reliability and stability of PCA results obtained from Week 3 data. First, interfactor correlations obtained during oblique rotation were used to assess divergent stability of Week 3 results (Campbell \& Fiske, 1959). Divergent stability is a measure of how well the components obtained at Week 3 were predictors of independent processes, and not two measurements of essentially the same underlying temperament trait. Second, the similarity of pattern matrices obtained through differing methods of rotation (oblique vs. orthogonal) was used to assess convergent validity of the factors at Week 3 (e.g., Budaev, 1997; King \& Figueredo, 1997). Convergent validity measures a component's strength to predict itself using different methods of prediction. Third, communalities of variables and magnitude of variable loadings obtained during PCA on Week 3 data were used to assess the strength of the relationships of variables in the Week 3 pattern matrix.

An additional analysis was used to address the longitudinal reliability of measurements obtained using Week 3 data. ${ }^{1}$ A comparison between the Week 3 pattern matrix $(n=73)$ and pattern matrices obtained through PCA of Week $6(n=37)$ and Week 9 data $(n=37)$ was used to assess whether the patterns of behaviors on components obtained at Week 3 were consistently found among behaviors across the entire study period. Although confirmatory factor analysis is the preferred analytical tool to compare pattern matrices between time points, the smaller sample sizes at Weeks 6 and 9 prevented the use of this analysis (our model would have resulted in a 15-variable, 37-subject model at each time point; confirmatory factor analysis requires a variable-to-subject ratio minimum of $1: 10$ to $1: 15$ ). Instead, component loadings were first normalized using Fisher's $r$-to-z ratio (Snedecor \& Cochran, 1980) and entered into a new $15 \times 12$ (Variables $\times$ Components at each week) data set. Pearson correlations (two-tailed) were then computed $(n=15)$ using the normalized component loadings across the four components and three time points (Weeks 3,6, and 9). Convergent stability of the components throughout the study period was assessed by high correlations between the same dimensions at different time points; divergent stability was assessed through relatively lower correlations between different dimensions at different time points.

\section{Data Analyses: Aim 2}

Profile analysis and canonical correlation were used to address the second aim of our study: Can temperamental trait development in a protostome be characterized according to current developmental themes normally used in vertebrate temperamental trait theory?

Profile analysis. This was the first analysis used to characterize the stability of expression levels of octopus temperamental traits through time. Composite scores were computed for each individual octopus that had data available for the entire testing period $(n=37)$ on the dimensions that arose from the Week 3 PCA (e.g., Stevenson-Hinde et al., 1980b). These scores were created for each temperament dimension by summing the behaviors that loaded most heavily $(> \pm .4$ ) on each component. Variables that met this criterion and had a negative factor loading were given a weight of -1 in the composite score equation, and variables meeting this criterion and having a positive factor loading were assigned a weight of +1 . For Component 1 , five behaviors satisfied this criterion and loaded positively. Component 2 contained five behaviors as well, with three loading positively and two negatively. Component 3 consisted of four behaviors, three of which loaded positively, and Component 4 had two positively loading behaviors and one negative. Composite scores were created for Weeks 3 , 6, and 9. For example, to create a composite score for Component 3 for an octopus at Week 6 based on the Week 3 pattern matrix, we added (positive loading) the observed number of times that individual octopus performed grab stimulus, pull stimulus, and posture change (behaviors that loaded highly on Component 3) during that week's testing, and we subtracted (negative loading) the number of times that individual octopus was observed to jet during that week's testing. Thus, each octopus had a set of 12 scores (4 temperament dimension scores at each of three time points).

The composite scores for the four temperament dimensions at each of the three time points were subjected to profile analysis, a type of repeatedmeasures multivariate analysis of variance, to assess parallelism (Tabachnick \& Fidell, 1996). Parallelism tests the hypothesis that there is no difference in the pattern of expression of the four temperament dimensions at each different time point. This analysis was considered the developmental function analysis because it described the normative pattern (Chalmers, 1987; Wohlwill, 1973) of all the octopuses in the study. Of particular interest in these tests is the interaction term between time and temperament dimension on composite score. A significant interaction means that the pattern of the four temperament dimensions relative to one another changes over time. A significant main effect in this analysis of either time or temperament dimension indicates that the composite scores for the entire sample changed across time or dimensions. Simple and deviation contrasts were used to examine pairings of time points (e.g., Week 3 vs. Week 6 , etc.) and temperament dimensions (Component 1 at Week 3 vs. Component 1 at Week 6, etc.) within any overall significant main effects, and graphical representations were used to help interpret significant interactions.

Canonical correlation. The second method used to address the characterization of temperamental trait development across time was canonical correlation (Tabachnick \& Fidell, 1996). Whereas profile analysis analyzed expression levels of traits for the study group as a whole, canonical correlation was used to understand the expression of traits across time at the level of the individual octopus. This analysis is a multivariate regression analysis and asks whether an octopus's four composite scores at a certain time point are predictive of the same scores at a later time point. Canonical correlations were computed only for those octopuses that were present throughout the testing period $(n=37)$. Correlations were run between the four composite scores at Week 3 and the four composite scores at Week $\sigma$ and between the four composite scores at Week 3 and the four composite scores at Week 9.

\section{Data Analysis: Aim 3}

A second profile analysis was conducted to address the third aim of our study: Are temperamental trait expression levels of octopuses influenced by their relatedness to one another? Individual octopuses were grouped by brood, and three broods (X,n=11;Y,n=19;I, $n=5)$ were used to assess differences in parallelism of composite score patterns across the three broods at the three different time points. The unequal number of broods tested reflects testing container availability, and not densities in holding tubs or total number of individuals present in each brood. Once again, simple and deviation contrasts were used to examine the pairings of broods, time points, and temperament dimensions within significant main effects, with graphical representations to aid in interpretation of significant interactions.

\footnotetext{
${ }^{1}$ We gratefully acknowledge an anonymous reviewer for this suggestion for longitudinal analysis.
} 


\section{Results}

During the three behavioral tests given across the 9 weeks, 15 behaviors were commonly recorded (see Table 1). All behaviors with the exception of touch stimulus, grab stimulus, and pull stimulus were observed in all three test situations at all three time points. Touch stimulus and grab stimulus occurred only during threat and feeding tests at all time points, whereas pull stimulus was only recorded during threat tests. Across the study period, individual octopuses consistently differed from one another in their magnitude of response and in their tendency to perform certain behaviors toward a given stimulus. However, although the magnitude of response within individual octopuses changed throughout the test period, the tendency for individuals to use the same approach toward the stimuli given in tests was consistent throughout the testing time.

\section{Can Behaviors in Octopuses Be Factored Reliably Into Categories Reflecting Dimensions of Temperament?}

$P C A$. Table 2 shows the pattern matrix obtained from PCA of the behaviors recorded during the 3rd week of life. A fourcomponent solution that accounted for $53 \%$ of the variance was chosen as the best-fit model on the basis of the criteria listed previously. The amount of variance explained in vertebrate studies normally ranges from $32.5 \%$ to $75.0 \%$ (e.g., Gosling, 1998; Sanson, Prior, \& Garino, 1987).

Naming of each factor or dimension is a subjective process but involves knowledge about the subject species and should reflect hypotheses concerning underlying causal relationships of the groupings of variables (Rummel, 1970). Selection of the factor names here were based on the behaviors that loaded highly ( $>$ \pm .4 ; see Note, Table 2) on each dimension (see Appendix). Active Engagement is defined by the behaviors crawl, touch stimulus, papillae change, color change, jet, and arm probe, and the second dimension, Arousal/Readiness, is characterized by head move, respiratory change, pupil change, no reaction (negative loading), and posture change (negative loading). A negative loading for a particular behavior means that the octopus had a tendency to not display that behavior when expressing that particular trait dimension. For example, the third dimension, Aggression, is characterized by grab stimulus, pull stimulus, and posture change (all high positive loadings) while not jetting from a stimulus (a high negative loading). The last dimension, Avoidance/Disinterest, is characterized by shrinking, papillae change, and not alerting toward a stimulus (negative loading). Individual octopuses can be ordered along each dimension through a description of the expression of particular behaviors that loaded highly on each dimension. For example, octopuses with stronger avoidance/disinterest tendencies could be expected to shrink, perform papillae changes, and not alert under our test conditions more than their less avoidant/ disinterested counterparts. This analysis indicated that discrete, observable behaviors in octopuses can be grouped to represent coherent dimensions of temperament.

Reliability of component structure. Convergent validity of the results obtained from the Week 3 PCA was assessed through the communalities of the 15 variables, the magnitude of their factor loadings, and comparison between pattern matrices derived using different factor rotation. For the pattern matrix in Table 2, communalities of all variables were .4 or above, with the exception of head move (.218). Similarly, 13 of the 15 variables had loadings of .52 or greater on one of the factors. The high communalities observed in combination with the strong factor loadings provided indications of convergent validity. Similarly, a comparison between oblique and orthogonal solutions revealed that there was no discrepancy in the loading of variables in regard to component (e.g., the behaviors making up each component were identical). The high invariance between oblique and orthogonal rotations represents additional evidence for the convergent validity of the factors obtained at Week 3. Discriminant validity of the four components at Week 3 was indicated by factor independence.

Table 2

Component Loadings of Frequency Counts of Behaviors Observed in 3-Week-Old Octopus bimaculoides on Four Direct-Oblimin Rotated Principal Components $(n=73)$

\begin{tabular}{|c|c|c|c|c|}
\hline Behavior & Active Engagement & Arousal/Readiness & Aggression & Avoidance/Disinterest \\
\hline Touch stimulus & .716 & -.096 & -.067 & .041 \\
\hline Crawl & .815 & .069 & -.225 & -.075 \\
\hline Papillae change & .649 & .284 & -.036 & .442 \\
\hline Color change & .715 & -.060 & .242 & -.170 \\
\hline Jet or swim & .544 & .188 & -.466 & -.155 \\
\hline Arm probe & .558 & -.271 & .138 & -.001 \\
\hline No reaction & -.351 & -.553 & -.353 & .346 \\
\hline Head move & .018 & .460 & .061 & .013 \\
\hline Respiratory change & -.022 & .615 & .190 & .112 \\
\hline Pupillary change & -.115 & .731 & -.095 & -.170 \\
\hline Posture change & .173 & -.498 & .440 & -.321 \\
\hline Grab brush & -.092 & .227 & .664 & .058 \\
\hline Pull brush & .012 & .043 & .626 & .100 \\
\hline Shrink & -.067 & -.030 & .082 & .693 \\
\hline Alert posture & -.059 & .057 & -.073 & -.707 \\
\hline \% variance explained & 20.3 & 13.3 & 10.2 & 9.2 \\
\hline$\%$ total variance from all components & 53.0 & & & \\
\hline
\end{tabular}

Note. Boldface type indicates the highest component loading(s) for each behavior. 
Although high interfactor correlations may indicate a lesser number of true factors present, low factor intercorrelations from the oblique factor solution (no correlation was greater than .15) were obtained in our sample. These provide evidence that the four dimensions reflect different aspects of temperament, satisfying the criteria of discriminant validity.

To assess the stability of the factor pattern across time, we correlated normalized component loadings from the Week 3 pattern matrix with the normalized component loadings from the Week 6 and Week 9 pattern matrices. A total of 53\% of the variance in the Week 6 data set and $51 \%$ of the variance in the Week 9 data set were explained by the 15-variable, fourcomponent model. The resulting $12 \times 12$ correlation matrix is summarized in Table 3 . As in multitrait-multimethod correlations, the correlation of the same components (Active Engagement, Arousal/Readiness, Aggression, Avoidance/Disinterest) across time are expected to exceed the correlations between different components. With the exception of the Week 6 to Week 9 correlation for Avoidance/Disinterest, correlations between pairings of the same components at Weeks 3,6 , and 9 were high (.425 to .772 ), with 9 out of 12 correlations reaching .05 significance levels. Notably, correlations between different components within and across time were consistently lower (.007 to .436), with 31 of the 36 correlations less than .30. All of the across-component correlations were nonsignificant. The high convergence within components across time, coupled with the corresponding divergence across components, strongly indicates the presence throughout the study period of the temperamental traits defined at Week 3 .

Overall, PCA analysis suggests that octopus behaviors can be grouped to form coherent dimensions of temperament. Reliability estimates at Week 3 and across Weeks 3,6, and 9 suggest that the groupings of behaviors in the Week 3 PCA are reliable indicators of enduring behavioral traits in octopuses throughout their first 9 weeks of life.

\section{Can Temperamental Trait Development in Octopuses Be Described According to Vertebrate Developmental Themes of Continuity and Change?}

Profile analysis. Figure 1 is the developmental function pattern for the four temperament dimensions across the three test points for all octopuses $(n=37)$. The profile analysis of parallelism revealed a significant interaction of time and temperament dimension, signifying different patterns of temperament trait expression for the 3 weeks tested, $F(6,216)=3.28, p<.05$. Post hoc tests revealed that the pattern of temperament dimensions between Weeks 3 and 6 was significantly different, whereas the pattern of temperament dimensions across Weeks 6 and 9 was stable. Arousal/readiness scores were significantly lower at Week 3 than at Week $6, F(1,36)=6.70, p<.05$, whereas aggression scores were significantly higher at Week 3 than at Week $6, F(1,36)=6.53, p<.05$. A decrease in active engagement scores from Week 3 to Week 6 was also observed, although this change was not significant. Changes in scores for avoidance/ disinterest across all three time points were minimal and were not significant. In general, consistency in expression levels was observed for two dimensions of temperamental traits (active engagement and avoidance/disinterest) across the testing period, but significant changes occurred during this same time on the other two (arousal/readiness and aggression) from Week 3 to 6 . Week 6 was not significantly different from Week 9 on any of the four behavioral composite scores. This first profile analysis characterized both change and continuity in the expression of temperamental traits in $O$. bimaculoides.

Canonical correlation. This analysis tested whether an individual octopus's rank-order composite scores at Week 3 were predictive of the same octopus's rank-order at Week 6 and 9. Table 4 summarizes the first two squared canonical correlations for each pairing. Although the canonical correlation models were not significant (Wilks's lambda $=.63$ ), $F(16,89)=0.92, p=.548$, this

Table 3

Pearson Correlation Coefficient Matrix Between Component Loadings for Week $3(n=73)$, Week $6(n=37)$, and Week $9(n=37)$ Pattern Matrices

\begin{tabular}{|c|c|c|c|c|c|c|c|c|}
\hline \multirow[b]{2}{*}{ Component } & \multicolumn{4}{|c|}{ Week 6} & \multicolumn{4}{|c|}{ Week 9} \\
\hline & 1 & 2 & 3 & 4 & 1 & 2 & 3 & 4 \\
\hline \multicolumn{9}{|c|}{ Week 3} \\
\hline $\begin{array}{l}\text { 1. } \mathrm{AE} \\
\text { 2. } \mathrm{A} / \mathrm{R} \\
\text { 3. } \mathrm{A} \\
\text { 4. } \mathrm{A} / \mathrm{D}\end{array}$ & $\begin{array}{r}-.485 \\
.259 \\
.136 \\
.107\end{array}$ & $\begin{array}{l}.209 \\
.588^{*} \\
.291 \\
-.256\end{array}$ & $\begin{array}{l}.181 \\
-.096 \\
-.536 * \\
-.019\end{array}$ & $\begin{array}{r}.053 \\
-.415 \\
.184 \\
-.590^{*}\end{array}$ & $\begin{array}{r}.425 \\
.132 \\
-.271 \\
-.179\end{array}$ & $\begin{array}{l}-.139 \\
-.587^{*} \\
-.325 \\
.194\end{array}$ & $\begin{array}{l}-.408 \\
.007 \\
.772 * * \\
.163\end{array}$ & $\begin{array}{r}.235 \\
-.182 \\
.096 \\
.460\end{array}$ \\
\hline \multicolumn{9}{|c|}{ Week 6} \\
\hline $\begin{array}{l}\text { 1. } \mathrm{AE} \\
\text { 2. } \mathrm{A} / \mathrm{R} \\
\text { 3. } \mathrm{A} \\
\text { 4. } \mathrm{A} / \mathrm{D}\end{array}$ & & & & & $\begin{array}{c}-.529 * \\
.034 \\
.161 \\
-.074\end{array}$ & $\begin{array}{l}-.088 \\
-.720^{* *} \\
.133 \\
-.094\end{array}$ & $\begin{array}{l}.196 \\
-.170 \\
-.721 * * \\
-.015\end{array}$ & $\begin{array}{r}.301 \\
.183 \\
.436 \\
-.069\end{array}$ \\
\hline
\end{tabular}

Note. Convergent correlations are in boldface and located along the diagonal. Off-diagonal correlations are indicators of divergent validity. $\mathrm{AE}=$ Active Engagement; $\mathrm{A} / \mathrm{R}=$ Arousal/Readiness; $\mathrm{A}=$ Aggression; $\mathrm{A} / \mathrm{D}=$ Avoidance/Disinterest.

${ }^{*} p=.05$, two-tailed. $* * p=.01$, two-tailed. 


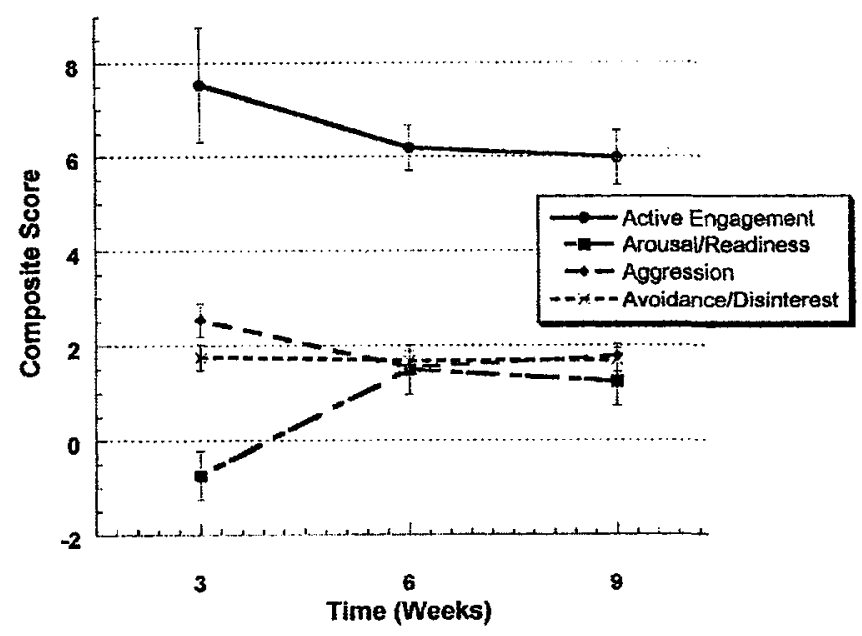

Figure 1. Normative profile of composite scores along four dimensions of temperament across three time points (Weeks 3,6, and 9) for Octopus bimaculoides $(n=37)$. Ertor bars represent standard error.

may be due to the small sample size relative to the number of variables (eight total: four composite scores representing independent variables and four composite scores representing dependent variables) in the model. The correlations themselves represent strong effect sizes (see Table 4). The first two canonical functions derived from Week 3 account for $39 \%$ of the variance in the Week 6 functions. In other words, if confidence could be obtained through satisfactory sample size, $39 \%$ of the variance in the four Week 6 temperament dimension scores might be predicted from the four Week 3 temperament scores. Similarly, Week 3 would explain 39\% of the variance in the Week 9 temperament scores, and Week 6 would account for $43 \%$ of the variance in the Week 9 temperament scores. These substantial correlations, although not conclusive, were considered as possible indicators of rank-order stability in octopus temperamental trait expression.

Overall, trait expression measurements indicated that the development of the four temperamental traits defined at Week 3 for $O$. bimaculoides can be characterized according to vertebrate developmental themes, that is, continuity and change.

\section{Is There an Effect of Relatedness on Temperamental Trait Development in Octopuses?}

A profile analysis by brood compared patterns of the temperament dimensions across time and three broods of octopuses: $\mathrm{Y}, \mathrm{I}$, and $\mathrm{X}$ (see Figure 2). A significant three-way interaction was

Table 4

Squared Canonical Correlations of the Four Temperament Dimensions Between Weeks 3, 6, and $9(n=37)$

\begin{tabular}{lcc}
\hline Weeks & $\begin{array}{c}\text { 1st squared } \\
\text { canonical correlation }\end{array}$ & $\begin{array}{c}\text { 2nd squared } \\
\text { canonical correlation }\end{array}$ \\
\hline 3 and 6 & .274 & .113 \\
3 and 9 & .266 & .120 \\
6 and 9 & .256 & .173 \\
\hline
\end{tabular}
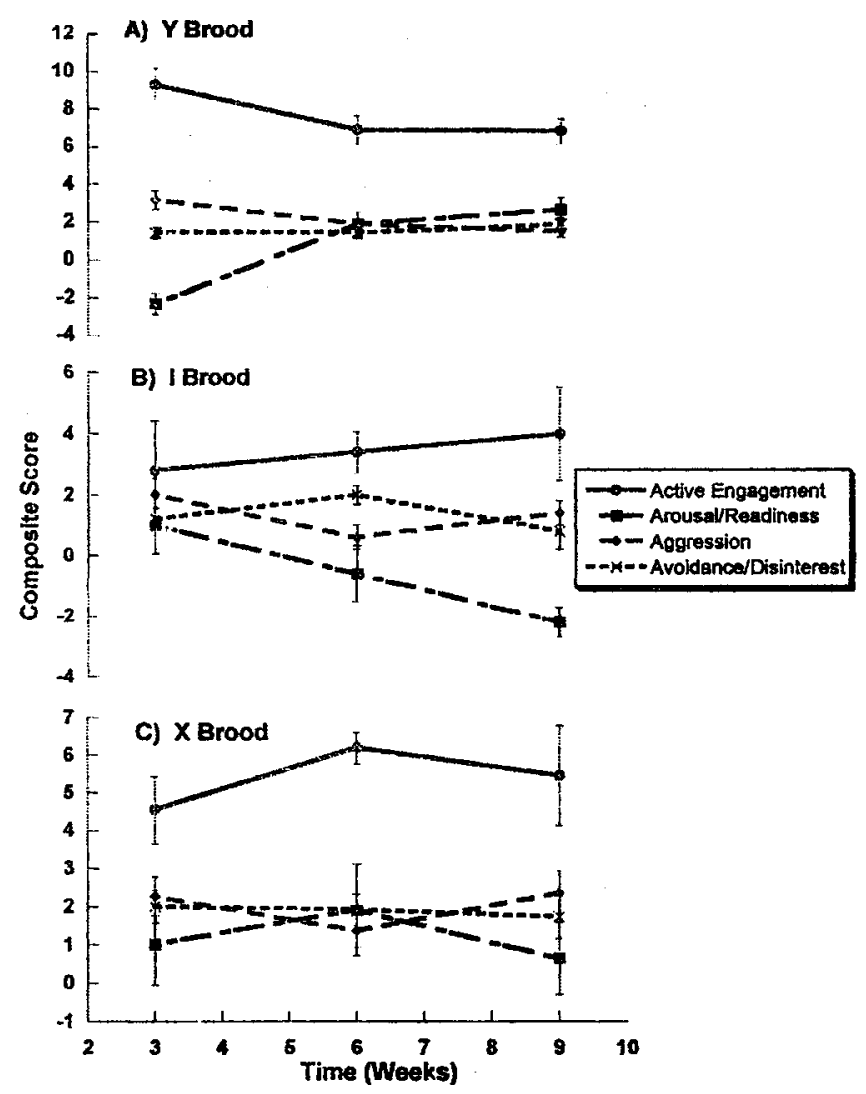

Figure 2. Puttern of composite scores along four dimensions of temperament across three time points (Weeks 3, 6, and 9) for three different broods of Octopus bimaculoides, A: Y brood $(n=19)$, B: I brood $(n=5)$, and $\mathrm{C}$ : $\mathrm{X}$ brood $(n=11)$. Error bars represent standard error.

found, $F(12,54)=3.69, p<.001$, signifying that the changes in temperament pattern across time were different for the broods. Post hoc tests revealed significant two-way interactions, indicating differences in patterns of temperament development across the three time points for $Y$ and I broods, $F(6,132)=4.51, p<.001$, and $Y$ and $X$ broods, $F(6,168)=4.21, p<.001$. A nonsignificant difference was found in the third pairing of broods, $\mathrm{X}$ and $\mathrm{I}$. Further post hoc contrasts revealed significant differences between $Y$ and $\mathrm{I}$ broods at Week $3, F(3,66)=6.78, p<.001$, and Week 9 , $F(3,66)=3.56, p<.05$, but not Week 6 . Among the four dimensions in this pairing, only arousal/readiness scores were found to differ significantly, $F(2,44)=11.86, p<.001$. Between $\mathrm{Y}$ and $\mathrm{X}$ broods, significant differences were found in the patterns of the four composite scores at Week $3, F(3,84)=7.69, p<.001$, but not at Week 6 or Week 9 . Once again, only arousal/readiness was found to have a significantly different pattern, $F(2$, $56)=8.01, p<.001$, between these two broods on the four dimensions of temperament. At the brood level, overall results indicate consistent scores along aggression and avoidance/disinterest profilcs, whereas change acruss broods was observed among the active engagement and arousal/readiness scores through time. Significant differences in the patterns of development among broods can be found between Weeks 3 to 6 and 6 to 9 , but these differences are mainly reflected in the pattern of arousal/readiness 
scores. To test whether size differences between broods influenced these results, we ran a one-way ANOVA between broods $Y$ and $I$ (brood $\mathrm{X}$ measurements were unavailable) for two categories of size measurement (mantle length and wet weight). At Day 14, mantle length and wet weight ranged from 5 to $8 \mathrm{~mm}$ and 0.4 to $2.0 \mathrm{~g}$, respectively, with nonsignificant differences between these two broods in both categories of measurement. No appreciable differences in size across broods were noted either during testing or at the end of the testing period. The growth rate of $O$. bimaculoides in the laboratory is a function of food and temperature (Forsythe \& Hanlon, 1988b). As food and temperature were held constant across octopuses and visible differences in sizes were not noted, their size was not considered to play a role in the resulting differences in behavioral expression across individual octopuses. This second profile analysis indicates a possible effect of relatedness on resulting temperamental trait development in young $O$. bimaculoides.

\section{Discussion}

Our results suggest that an octopus's behavioral development through its first 9 weeks of life is an idiosyncratic, individualistic process. We propose that this development occurs along at least four rudimentary dimensions of temperament that are expressed by the 3rd week of life. A total of 15 observable, discrete behaviors can be reliably factored into these four dimensions of temperament and can then be used to characterize behavioral development across the first 9 weeks of life in these organisms. So that we may be consistent with current psychological research in humans and other primates, we have chosen to call these early occurring behavioral dimensions temperamental traits in 0 . bimaculoides. Although scores obtained on these four dimensions at Week 3 were not clearly predictive of later tendencies at Weeks 6 and 9 , our data suggest that heterotypic continuity among traits is observed throughout the first 9 weeks of life. By this, we mean that individual octopuses consistently differ from one another in the degree of response or tendency to behave in a certain way, but a significant amount of this variation can be described along the trait dimensions of active engagement, arousal/readiness, aggression, and avoidance/disinterest. Furthermore, our results indicate that developmental trajectories along these four temperament dimensions are more similar among related octopuses than nonrelated ones. Because of the early developmental history of our octopuses and lack of knowledge concerning parental genotypes, generalizations from this last aspect of our study are somewhat limited. Still, this study provides preliminary evidence for the possibility that expression levels of temperamental traits are influenced at least in part by the genotype of an octopus, a result that would be consistent with findings among vertebrates (snakes, Herzog \& Burghardt, 1988; goats, Lyons, Price, \& Moberg, 1988; fishes, Iguchi, Matsubara, \& Hakoyama, 2001).

\section{Adaptive Individuality of Young Octopuses}

Even though the main purpose of this study was to document the basic phenomenon of temperamental traits in octopuses, we believe it is worthwhile to consider how and why these organisms, supposedly "lower" invertebrates, display a psychological trait normally reserved for vertebrates with fundamentally different life histories and body plans. Although individual differences can arise under nonadaptive or neutral scenarios such as genetic drift, neutrality, or equivalent fitness for alternative traits (A. B. Clark \& Ehlinger, 1987; Hendrick, 1983), temperamental trait features are also considered to be adaptive in nature, conferring to populations advantages not obtained through behavioral plasticity alone (A. B. Clark \& Ehlinger, 1987; Sterrer, 1992). With deference to these alternate possibilities then, we consider how temperament may be adaptive in octopuses under two scenarios and outline a third possibility for the adaptiveness of innate behavioral tendencies in this group.

The application of game theory to behavioral analyses (Maynard-Smith, 1982) suggests that the relative value or success of behavioral phenotypes will depend on the behavioral phenotypes of conspecific associates and will often be maintained through frequency or density-dependent selection. Close associates may be close relatives, which can result in same-age siblings being intense competitors. Within vertebrate social systems, humans and other animals often differ from one another in social and psychological characteristics such that direct or indirect competition with siblings is reduced (D. M. Buss, 1991; A. B. Clark \& Ehlinger, 1987). In the octopuses, little is known concerning adult social systems, but at best their social structure might be considered loose. Most researchers consider the adults to be solitary, but with overlapping home ranges (Hartwick, Ambrose, \& Robinson, 1984; Mather \& O'Dor, 1991). Little is known concerning social interactions of juvenile octopuses. However, $O$. bimaculoides young immediately assume a benthic existence and are thought to disperse through crawling or swimming (Lang, 1997). Large numbers of related young $O$. bimaculoides hatch simultaneously in laboratory conditions ( $\operatorname{Sinn}, 2000$ ), and field studies have indicated peak hatching seasons for another closely related octopus species ( $O$. bimaculatus; Ambrose, 1988). During periods when large numbers of octopuses are hatching simultaneously combined with an initial means of slow dispersal, competition for food and shelter resources with siblings or conspecifics (or both) could occur (Ambrose, 1988; Anderson, 1997). From an evolutionary perspective, this competition would be keenest among those pursuing the same behavioral profile strategy (D. M. Buss, 1991). Selection may favor mechanisms that cause some octopuses to seek niches where the competition is less intense and hence where the average payoff may be higher (D. M. Buss \& Greiling, 1999). Thus, juvenile octopuses competing within the same space and time may benefit from an individualistic behavioral approach to their environment. Individual variation in behavioral approaches across all octopuses in our tests (observed in testing and indicated by standard error bars, Figures 1 and 2) and the higher inter- versus intrabrood variation (Figure 2) may allow for unique behavioral niche occupation arrong individual octopuses within broods and among conspecifics.

A second scenario that could drive the formation of adaptive individual differences in octopuses is their occupation of a heterogeneous environment that is unpredictable or fluctuating through time (A. B. Clark \& Ehlinger, 1987; Mather \& Anderson, 1993). If environments that newly hatched or juvenile octopuses inhabit are unpredictable, variability around temperamental profiles in offspring could be advantageous. Near-shore reef habitats of shallow-water octopuses are highly fluctuating along spatial and temporal scales (Anderson, 1997). For example, highly actively 
engaged and not very avoidant or disinterested octopuses might be expected to have lower rates of survival under conditions of low prey and high predator densities, whereas these same octopuses may be very successful under conditions where predator densities are lower. Indeed, two field studies, primarily designed to test other aspects of octopus behavior, have secondarily described this principle. Mather and O'Dor (1991) found juvenile O. vulgaris to have survival success rates directly attributable to their activity levels and corresponding predator densities. Hanlon, Forsythe, and Joneschild (1999) observed interpopulation differences in phenotypic expression of behavioral traits in wild adult $O$. cyanea and ascribed these observed differences to differential predator densities encountered by octopuses across the two populations. If environment at birth is unpredictable, then maintenance of variability in behavioral profiles through stabilizing selection could be one means of ensuring survival of the largest number of octopus offspring.

Finally, the life history of octopuses may indicate an increased need for innate behavioral variation. With the exception of snakes (Herzog \& Burghardt, 1988), octopuses are unique in comparison to the vertebrates previously studied for these types of traits in that their young receive no parental care (Boletzky, 1987) and yet must survive immediately in the same complex environment that is occupied by their parents (Wells, 1962a). Although very little is known concerning the genetic basis of behavior in the cephalopods, Wells (1958, 1962a, 1962b) postulated that innate components of behavior must play a major role in the early life of their young to ensure survival. The formation of strong endogenous behavioral adaptations such as temperamental traits may have also been driven in octopuses by their life history traits, such as lack of postnatal care.

\section{Patterns of Temperament Trait Development in the Early Life of $\mathrm{O}$. bimaculoides}

In general, young octopuses can be described at Week 3 relative to Week 6 and Week 9 as being more actively engaged in their environment, not as aroused or ready, more aggressive, and equally avoidant or disinterested. Why might it be important for these octopuses to be more highly mobile (see behaviors and their relationships to the factors, Appendix) while also attacking or being more aggressive in their initial responses to stimulus at Week 3 in comparison to Weeks 6 and 9? Higher scores along aggression and active engagement dimensions might be indicators of a biological drive to disperse in the wild. An early tendency toward movement has been postulated to serve dispersal purposes in other octopods (O. joubini; Mather, 1984). Higher levels of aggression at this earlier age could also contribute to this dispersal if octopuses are acting aggressively toward conspecifics, driving each other away during encounters (Lorenz, 1963).

Arousal/readiness mechanisms are thought to mediate the preparation for fight or flight responses in mammals (A. H. Buss \& Plomin, 1984). The increase in arousal/readiness tendencies witnessed here from Week 3 to Week 6 (Figure 1) may indicate the increased use of arousal input to mediate fight or flight responses. The increased use of behaviors making up arousal measures (see Table 2 and Appendix) concurrent with the decrease in active moving behaviors (e.g., variables making up the trait dimensions of active engagement and aggression) during Weeks 3 to 6 sug- gests an increased tendency by young octopuses during this time to assess situations before necessarily acting in them. Further studies are needed to test the interaction between temperamental trait development and ecology in octopuses.

\section{Temperamental Trait Dimensional Structure in Octopuses}

Our results indicate that octopus temperamental traits can be characterized according to developmental theory primarily developed for vertebrate taxa. The four octopus factors found in this study display heterotypic continuity from Weeks 3 to 6 and homotypic continuity from Weeks 6 to 9 . Our results suggest that within this trait dimension continuity, expression levels of octopuses change on the first three dimensions for either the entire group or between broods. These changes occurred for either the entire testing group from Week 3 to Week 6 or among one brood pairing from Weeks 6 to 9 . Stability of expression levels was observed throughout the entire study for all octopuses on the fourth dimension, Avoidance/Disinterest. As Chess and Thomas (1990) have pointed out, continuity and change are not mutually exclusive. A temperamental pattern or characteristic may be stable for a period and then change. Change may arise through the process of organism-environment interaction, a dynamic self-regulating system (Thelen, 1990). Continuity in individual differences can be a result of heredity, stable situational characteristics, or consistent experience (A. H. Buss \& Plomin, 1984), but genes can contribute to behavioral change as well (Plomin, 1986). Thus, temperament characteristics are modified by changes in behavioral organization, such as those based on maturation of neurological organization, and by exogenous factors, such as a change in an environmental parameter. Because experiential conditions were controlled during experimentation, our results suggest at least some endogenous influence on octopus temperamental change during Weeks 3 to 6 (but not for the trait dimension avoidance/disinterest). The stability witnessed from Weeks 6 to 9 could be due either to endogenous processes or to the stability of the environment that was encountered in our laboratory conditions.

Whether an individual octopus's temperamental trait levels at Week 3 predict later behavioral tendencies is unclear. Even though individual expression levels on the four temperamental trait dimensions at Week 3 are predictive of large amounts (around 40\%) of variance in later scores, the results are not significant. This aspect of our study needs replication. In humans, some behavioral traits (e.g., fear) have been found to be predictive of later outcomes whereas others (e.g., early proneness to anger) have not (Rothbart et al., 2000).

\section{Conclusions}

Although the present findings (a) are based on reliable observational dala obtained through a variety of test procedures, (b) were obtained consistently throughout the study period, and (c) formed conceptually coherent dimensions, they may not represent all potential temperamental trait dimensions that are present in octopuses. Other studies may reveal more dimensions or differing structural organization of octopus temperament dimensions through time because of species differences or environmental conditions. Furthermore, the interaction of octopus genotype with our laboratory conditions may have differed by brood and either 
increased or masked differences obtained in composite scores. The best evidence that the octopus temperamental traits are accurate descriptors must ultimately come from construct validation procedures. The previously noted reliability and stability analyses of the octopus temperamental factors exemplified one aspect of this construct validity. The most convincing validation will come from correlation of these factors with observable behaviors in other contexts and studies (King \& Figueredo, 1997), an aspect of human personality validity research that has a long history with only modest success (Nisbett \& Ross, 1991).

Still, octopuses can be described as displaying temperamental traits with the same level of confidence that is obtained from studies of other taxa, including primates. Although the earliest studies on the longitudinal nature of individual differences have concerned humans and other nonhuman primates (Mednick, Harway, \& Finello, 1984; Plomin \& Dunn, 1986; Stevenson-Hinde et al., 1980a, 1980b), other vertebrate taxa have recently been included in these types of designs in a comparative attempt to understand the formation and development of these trait styles (wolves, MacDonald, 1983; goats, Lyons et al., 1988; fishes, Francis, 1990). Analysis of octopus temperament offers challenges to a field currently dominated by vertebrate studies. Temperamental trait studies among protostomes offer researchers a chance to look for universals and differences in temperamental trait features in organisms whose developmental timing is different from vertebrates. Common functional features of temperamental traits between octopuses and vertebrates may be highly informative of convergent evolutionary mechanisms. Contrasting life history traits, such as parental influence in the immediately postnatal period and the resulting behavioral adaptations, between these two groups may give researchers insight into the processes of divergent evolutionary phenomenon.

Octopuses are behaviorally complex representatives of the protostome lineage, and our study provides some of the first evidence that their young can be characterized according to current temperamental trait theory and development. Ultimately, psychological testing across a wider range of vertebrate and invertebrate taxa such as the octopuses may be most useful in furthering understanding of the evolution of individuality itself.

\section{References}

Ambrose, R. F. (1988). Population dynamics of Octopus bimaculatus: Influence of life history patterns, synchronous reproduction and recruitment. Malacologia, 29, 23-39.

Anderson, T. J. (1997). Habitat and shelter use by Octopus tetricus. Marine Ecology Progress Series, 150, 137-148.

Armitage, K. B. (1986). Individuality, social behavior, and reproductive success in yellow-bellied marmots. Ecology. 67, 1186-1193.

Barnes, R. D. (1987). Invertebrate zoology (5th ed). New York: Harcourt Brace Jovanovich.

Boal, J. G., \& Ni, J. N. (1996). Ventilation rate of cuttlefish, Sepia officinalis, in response to visual stimuli. The Veliger, 39, 342-347.

Boletzky, S. v. (1987). Juvenile behavior. In P. R. Boyle (Ed.), Cephalopod life cycles: Vol. II. Comparative reviews (pp. 45-60). London: Academic Press.

Bonavita-Cougourdan, A., \& Morel, L. (1988). Interindividual variability and idiosyncrasy in social behaviours in the ant Camponotus vagus Scop. Ethology, 77, 58-66.

Boyle, P. R. (1983). Ventilation rate and arousal in the octopus. Journal of Experimental Marine Biology and Ecology, 69, 129-136.
Boyle, P. R. (Ed.). (1987). Cephalopod life cycles: Vol. II. Comparative reviews. London: Academic Press.

Braungart, J. M., Plomin, R., DeFries, J. C., \& Fulker, D. W. (1992). Genetic influence on tester-rated infant temperament as assessed by Bayley's infant behavior record: Nonadoptive siblings and twins. Developmental Psychology, 28, 40-47.

Budaev, S. V. (1997). "Personality" in the guppy (Poecilia reticulata): A correlational study of exploratory behavior and social tendency. Journal of Comparative Psychology, 111, 399-411.

Budelmann, B. U., \& Young, J. Z. (1993). The oculomotor system of decapod cephalopods: Eye muscles, eye muscle nerves, and the oculomotor neurons in the central nervous system. Philosophical Transactions of the Royal Society of London, Series B, 340, 93-125.

Buss, A. (1989). Temperaments as personality traits. In G. A. Kohnstamm, J. E. Bates, \& M. K. Rothbart (Eds.), Temperament in childhood (pp. 49-58). New York: Wiley.

Buss, A. H., \& Plomin, R. (1984). Temperament: Early developing personality traits. London: Erlbaum.

Buss, D. M. (1991). Evolutionary personality psychology. Annual Review of Psychology, 42, 459-491.

Buss, D. M., \& Greiling, H. (1999). Adaptive individual differences. Journal of Personality, 67, 209-243.

Campbell, D. T., \& Fiske, D. W. (1959). Convergent and discriminant validation by the multitrait-multimethod matrix. Psychological Bulletin, 56, 81-105.

Carnicero, J. A. C., Perez-Lopez, J., Salinas, M. C. G., \& MartinezFuentes, M. T. (2000). A longitudinal study of temperament in infancy: Stability and convergence of measures. European Journal of Personality, $14,21-37$.

Caspi, A. (1998). Personality development across the life course. In W. Damon (Series Ed.) \& N. Eisenberg (Vol. Ed.), Handbook of child psychology: Vol. 3. Social, emotional, and personality development (pp. 311-388). New York: Wiley.

Cattell, R. B. (1966). The scree test for the number of factors. Sociological Methods and Research, 1, 245-276.

Cattell, R. B., \& Peterson, D. R. (1959). Personality structure in four and five year olds in terms of objective tests. Journal of Clinical Psychology, 15, 355-369.

Chalmers, N. R. (1987). Developmental pathways in behaviour. Animal Behaviour, 35, 659-674.

Chase, R., \& Wells, M. J. (1986). Chemotactic behaviour in Octopus. Journal of Comparative Physiology A, 158, 375-381.

Chess, S., \& Thomas, A. (1990). The New York longitudinal study (NYLS): The young adult periods. Canadian Journal of Psychiatry, 35, 557-561.

Clark, A. B., \& Ehlinger, T. J. (1987). Pattern and adaptation in individual behavioral differences. In P. P. G. Bateson \& P. H. Klopfer (Eds.), Perspectives in ethology (Vol. 7, pp. 1-47). New York: Plenum.

Clarke, A. S. (1993). Social rearing effects on HPA axis activity over early development and in response to stress in young rhesus monkeys. Developmental Psychobiology, 26, 443-447.

Clarke, A. S., \& Boinski, S. (1995). Temperament in nonhuman primates. American Journal of Primatology, 37, 103-125.

Depue, R. A. (1995). Neurobiological factors in personality and depression. European Journal of Personality, 9, 413-439.

Feaver, J., Mendl, M., \& Bateson, P. (1986). A method for rating the individual distinctiveness of cats. Animal Behaviour, 34, 1016-1025.

Forkman, B., Furuhaug, I. L., \& Jensen, P. (1995). Personality, coping patterns, and aggression in piglets. Applied Animal Behavior Science, $45,31-42$.

Forsythe, J. W., \& Hanlon, R. T. (1988a). Behavior, body patterning and reproductive biology of Octopus bimaculoides from California. Malacologia, 29, 41-45.

Forsythe, J. W., \& Hanlon, R. T. (1988b). Effects of temperature on 
laboratory growth, reproduction and life-span of Octopus bimaculoides. Marine Biology, 98, 369-379.

Fox, N. A., \& Henderson, H. A. (1999). Does infancy matter? Predicting social behavior from infant temperament. Infant Behavior \& Development, 22, 445-455.

Francis, R. C. (1990). Temperament in a fish: A longitudinal study of the development of individual differences in aggression and social rank in the Midas cichlid. Ethology, 86, 311-325.

Goldsmith, H. H., Buss, A. H., Plomin, R., Rothbart, M. K., Thomas, A., Chess, S., Hinde, R. A., \& McCall, R. B. (1987). What is temperament? Four approaches. Child Development, 58, 505-529.

Gosling, S. D. (1998). Personality dimensions in spotted hyenas (Crocuta crocuta). Journal of Comparative Psychology, 112, 107-118.

Gosling, S. D. (2001). From mice to men: What can we learn about personality from animal research? Psychological Bulletin, 127, 45-86.

Gosling, S. D., \& John, O. P. (1999). Personality dimensions in nonhuman animals: A cross-species review. Current Directions in Psychological Science, 8, 69-75.

Hanlon, R. T., Forsythe. J. W., \& Joneschild, D. E. (1999). Crypsis, conspicuousness, mimicry and polyphenism as antipredator defences of foraging octopuses on Indo-Pacific coral reefs, with a method of quantifying crypsis from video tapes. Biological Journal of the Linnean Society, 66, 1-22.

Hanlon, R. T., \& Messenger, J. B. (1996). Cephalopod behaviour. Cambridge, England: Cambridge University Press.

Hartwick, E. B., Ambrose, R. F., \& Robinson, S. M. C. (1984). Den utilization and the movements of tagged Octopus dofleini. Marine Behaviour and Physiology, 11, 95-110.

Hendrick, P. W. (1983). Genetics of populations. Boston: Science Books.

Herzog, H. A., Jr., \& Burghardt, G. M. (1988). Development of antipredator responses in snakes III: Long-term stability of litter and individual differences. Ethology, 77, 250-258.

Hubert, N. C., Wachs, T. D., Peters-Martin, P., \& Gandour, M. J. (1982). The study of early temperament: Measurement and conceptual issues. Child Development, 53, 571-600.

Iguchi, K., Matsubara, N., \& Hakoyama, H. (2001). Behavioural individuality assessed from two strains of cloned fish. Animal Behaviour, 61, 351-356.

Kagan, J. (1969). The three faces of continuity in human development. In D. A. Goslin (Ed.), Handbook of socialization theory and research (pp. 983-1002). Chicago: Rand McNally.

Kagan, J., \& Snidman, N. (1991). Infant predictors of inhibited and uninhibited profiles. Psychological Science, 2, 40-44.

Katano, O. (1987). Social structure of the dark chub, Zacco temmincki, in a small pond in relation to individual differences. Physiology and Ecology in Japan, 24, 1-132.

Kim, J. O., \& Mueller, C. W. (1978). Factor analysis: Statistical methods and practical issues. In M. S. Lewis-Beck (Ed.), Sage University paper series on quantitative applications in the social sciences (pp. 1-88). London: Sage.

King, J. E., \& Figueredo, A. J. (1997). The five-factor model plus dominance in chimpanzee personality. Journal of Research in Personality, 31, 257-271.

Lang. M. A. (1997). Octopus bimaculoides. In M. A. Lang \& F. G. Hochberg (Eds.), Proceedings of the Workshop on the Fishery and Market Potential of Octopus in California (pp. 1-9). Washington, DC: Smithsonian Institution.

Lorenz, K. (1963). On aggression. London: Harcourt Brace Jovanovich.

Lyons, D. M., Price, E. O., \& Moberg, G. P. (1988). Individual differences in temperament of domestic dairy goats: Constancy and change. Animal Behaviour, 36, 1323-1333.

MacDonald, K. (1983). Stability of individual differences in behavior in a litter of wolf cubs (Canis lupus). Journal of Comparative Psychology, 97, 99-106.
Maestripieri, D. (2000). Measuring temperament in rhesus macaques: Consistency and change in emotionality over time. Behavioural Processes, 49, 167-171.

Maldonado, H. (1964). The control of attack by Octopus. Zeitshrift fir Vergleichende Physiologie, 47, 656-674.

Mather, J. A. (1984). Development of behaviour in Octopus joubini Robson, 1929. Vie et Milieu, 34, 17-20.

Mather, J. A. (1991). Foraging, feeding, and prey remains in middens of juvenile Octopus vulgaris (Mollusca: Cephalopoda). Journal of Zoology (Landon), 224, 27-39.

Mather, J. A., \& Anderson, R. C. (1993). Personalities of octopuses (Octopus rubescens). Journal of Comparative Psychology, 107, 336340.

Mather, J. A., \& Anderson, R. C. (1999). Exploration, play, and habituation in octopuses (Octopus dofleini). Journal of Comparative Psychology, 113, 333-338.

Mather, J. A., \& O'Dor, R. K. (1991). Foraging strategies and predation risk shape the natural history of juvenile Octopus vulgaris. Bulletin of Marine Science, 49, 256-269.

Maynard-Smith, J. (1982). Evolution and the theory of games. Cambridge, England: Cambridge University Press.

Maynard-Smith, J., \& Harper, D. G. C. (1988). The evolution of aggression: Can selection generate variability? Philosophical Transactions of the Royal Society of London, Series B, 319, 557-570.

McGue, M., \& Bouchard, T. J. (1998). Genetic and environmental influences on human behavioral diffeiences. Annual Review of Neuroscience, 21, 1-24.

Mednick, S. A., Harway, M., \& Finello, K. M. (Eds.). (1984). Handbook of longitudinal research: Vol. 1. Birth and childhood cohorts. New York: Praeger.

Merenda, P. F. (1999). Theories, models, and factor approaches to personality, temperament, and behavioral types: Postulations and measurement in the second millennium A.D. Psychological Reports, 85, 905-932.

Messenger, J. B. (1977). Prey-capture and learning in the cuttlefish, Sepia. Symposia of the Zoological Society of London, 38, 347-376.

Montanelli, R. G., \& Humphreys, L. (1976). Latent roots of random data correlation matrices with squared multiple correlations on the diagonal: A Monte Carlo study. Psychometrika, 32, 341-348.

Nisbett, R. E., \& Ross, L. (1991). The person and the situation: Perspectives of social psychology. New York: McGraw-Hill.

Pflumm, W., \& Wilhelm, K. (1982). Olfactory feedback in the scent marking behaviour of foraging honeybees at the food source? Physiological Entomology, 7, 203-207.

Pickford, (i. E., \& McConnaughey, B. H. (1949). The Octopus bimaculatus problem: A study in sibling species. Bulletin of the Bingham Oceanographic Collection, 12, 1-66.

Plomin, R. (1981). Heredity and temperament: A comparison of twin data for self-report questionnaires, parental ratings, and objectively assessed behavior. In L. Gedda, P. Parisi, \& W. E. Nance (Eds.), Progress in clinical and biological research: Vol. 69B. Twin research 3, Part B, Intelligence, personality, and development. New York: Alan R. Liss.

Plomin, R. (1986). Development, genetics, and psychology. Hillsdale, NJ: Erlbaum.

Plomin, R. (2000). Behavioural genetics in the 21st century. International Journal of Behavioral Development, 24, 30-34.

Plomin, R., \& Dunn, J. (1986). The study of temperament: Changes, continuities, and challenges. Hillsdale, NJ: Erlbaum.

Reale, D., Gallant, B. Y., LeBlanc, M., \& Festa-Bianchet, M. (2000). Consistency of temperament in bighom ewes and correlates with behaviour and life history. Animal Behaviour, 60, 589-597.

Retana, J., \& Cerda, X. (1991). Behavioural variability and development of Cataglyphis cursor ant workers (Hymenoptera, Formicidae). Ethology. 89, 275-286. 
Riese, M. L. (1987). Temperament stability between the neonatal period and 24 months. Developmental Psychology. 23, 216-222.

Rothbart, M. K. (1986). Longitudinal observations of infant temperament. Developmental Psychology, 22, 356-365.

Rothbart, M. K., Ahadi, S. A., \& Evans, D. E. (2000). Temperament and personality: Origins and outcomes. Journal of Personality and Social Psychology, 78, 122-135.

Rummel, R. J. (1970). Applied factor analysis. Evanston, IL: Northwestern University Press.

Sackett, G. P., Sameroff, A. J., Cairns, R. B., \& Suomi, S. J. (1981). Continuity in behavioral development: Theoretical and empirical issues. In K. Immeimann, G. W. Barlow, L. Petrinovich, \& M. Main (Eds.), Behavioral development: The Bielefeld interdisciplinary project (pp. 23-57). New York: Cambridge University Press.

Sanson, A., Prior, M., \& Garino, E. (1987). The structure of infant temperament: Factor analysis of the Revised Infant Temperament Questionnaire. Infant Behavior and Development, 10, 97-104.

Sinn, D. L. (2000). A longitudinal assessment of temperament in Octopus bimaculoides. Unpublished master's thesis, Portland State University, Portland, Oregon.

Slater, P. J. B. (1981). Individual differences in animal behavior. In P. P. G. Bateson \& P. H. Klopfer (Eds.), Perspectives in ethology (Vol. 4, pp. 35-49). New York: Plenum.

Snedecor, G. W., \& Cochran, W. G. (1980). Statistical methods (7th ed.). Ames, IA: Iowa State University Press..

SPSS for Windows (Version 8.0.0) [Computer software]. (1997). Chicago: Author.

Sterrer, W. (1992). Prometheus and Proteus: The creative, unpredictable individual in evolution. Evolution and Cognition, 1, 101-129.

Stevenson-Hinde, J., Stillwell-Barnes, R., \& Zunz, M. (1980a). Individual differences in young thesus monkeys: Continuity and change. Primates, 21, 498-509.

Stevenson-Hinde, J., Stillwell-Barnes, R., \& Zunz, M. (1980b). Subjective assessment of rhesus monkeys over four successive years. Primates, 21 . 66-82.

Strelau, J. (1989). The regulative theory of temperament as a result of east-west influences. In G. A. Kohnstamm, J. E. Bates, \& M. K. Rothbart (Eds.), Temperament in childhood (pp. 35-48). New York: Wiley.

Suomi, S. J. (1987). Genetic and maternal contributions to individual differences in rhesus monkey biobehavioral development. In N. Kras- negor, E. Blass, M. Hofer, \& W. Smotherman (Eds.), Perinatal development: A psychobiological perspective (pp. 397-420). New York: Academic Press.

Suomi, S. J., Novak, M. A., \& Well, A. (1996). Aging in thesus monkeys: Different windows on behavioral continuity and change. Developmental Psychology, 32, 1116-1128.

Tabachnick, B. G., \& Fidell, L. S. (1996). Using multivariate statistics (3rd ed.). New York: HarperCollins.

Talwar, R., Nitz, K., Lerner, J. V., \& Lerner, R. M. (1991). The functional significance of organismic individuality: The sample case of temperament. In J. Strelau \& A. Angleitner (Eds.), Explorations in temperament: International perspectives on theory and measurement (pp. 29-42). New York: Plenum.

Thelen, E. (1990). Dynamical systems and the generation of individual differences. In J. Colombo \& J. Fagen (Eds.), Individual differences in infancy: Reliability, stability, prediction (pp. 19-43). Hillsdale, NJ: Eribaum.

Thomas, A., \& Chess, S. (1977). Temperament and development. New York: Brunner/Mazel.

Turkheimer, E. (1998). Heritability and biological explanation. Psychological Review, 105, 782-791.

Wells, M. J. (1958). Factors affecting reactions to Mysis by newly hatched Sepia. Behaviour, 13, 96-111.

Wells, M. J. (1962a). Brain and behaviour in cephalopods. Stanford, CA: Stanford University Press.

Wells, M. J. (1962b). Early learning in Sepia. Symposia of the Zoological Society of London, 8, 149-169.

Wilson, D. S., Coleman, K., Clark, A. B., \& Biederman, L. (1993). Shy-bold continuum in pumpkinseed sunfish (Lepomis gibbosus): An ecological study of a psychological trait. Journal of Comparative Psychology, 107, 250-260.

Wohlwill, J. F. (1973). The study of behavioral development. New York: Academic Press.

Wray, G. A., Levinton, J. S., \& Shapiro, L. H. (1996, October 25). Molecular evidence for deep Precambrian divergences among metazoan phyla. Science, 274, 568-573.

Yarnall, J. L. (1969). Aspects of the behaviour of Octopus cyanea Gray. Animal Behaviour, 17, 747-754.

Zwick, W. R., \& Velicer, W. F. (1986). Comparison of five rules for determining the number of components to retain. Psychological Bulletin, 99, 432-442. 


\title{
Appendix
}

\author{
Naming of the Factors
}

\section{Active Engagement}

The behaviors crawl, jet, papillae change, and color change were considered to be indicators of activity in this first dimension either through active moving (crawl and jet) or internal arousal (papillae and color changing). Active arm movements (arm probe and touch stimulus) suggest engagement or active information gathering (Mather \& Anderson, 1999). Chemotactile exploration is described by Yarnall (1969) for $O$. cyanea and by Mather (1991) for juvenile $O$. vulgaris; both used the term speculative hunting. Mather and O'Dor (1991) suggested that the learning capacity for octopuses dictates that they explore their habitat. Active engagement encompasses these traits in young octopuses and would provide the initial substrate on which later tendencies are shaped through experience. Activity has been proposed as a major axis of individual differences for a number of different organisms across a wide range of taxa (Gosling \& John, 1999), including humans (A. H. Buss \& Plomin, 1984) as well as octopuses (Mather \& Anderson, 1993). The naming of this dimension for young $O$. bimaculoides differs from these other taxa (including $O$. rubescens) because of additional behaviors that define this dimension (touch stimulus, arm probe, papillae change, color change) and that imply a broader meaning than simple displacement movements.

\section{Arousal/Readiness}

The second dimension was named to indicate behaviors that could be interpreted as an assessment exercise or readiness toward a stimulus or object. Octopuses are known to use monocular parallax as a means of focusing on prey or other objects (Hanlon \& Messenger, 1996; Maldonado, 1964; Wells, 1962a), a behavior that involves moving the eye physically between two points to triangulate a distance. The behavior of head move. which loaded highly on this dimension, involved moving the eyes in either a vertical up and down movement or a horizontal side to side, which could indicate possible parallax or an attempt at focusing. Widening of the pupil in octopuses, when associated with movement of objects near the animal, is also thought to reduce the depth of focus to permit more accurate ranging (Budelmann \& Young, 1993; Messenger, 1977). Pupil changes loaded highly on this dimension in combination with head movements, whereas a negative loading for posture change indicated that the octopuses had a tendency to not perform other body movements. Active engagement movement behaviors did not load on this dimension, which is important because naming of the factors includes assessment concerning variables that do not load highly on a particular dimension (Rummel, 1970). Respiratory changes, also included in this dimension, have been shown to be a measure of an octopus's motivational state (Boyle, 1983; Chase \& Wells, 1986) as well as being an indicator of arousal in cuttlefish (Boal \& Ni, 1996).

\section{Aggression}

The third dimension was characterized by behaviors that were performed directly and immediately toward the stimulus, either a brush or a crab. Grabbing stimulus or pulling stimulus while not jetting or fleeing from it was considered to be an indicator of aggressiveness.

\section{Avoidance/Disinterest}

Alert posture was interpreted as an individual's interest in a particular stimulus and has been described as vigilant activity in the wild (Hanlon et al., 1999). Alert posture loaded negatively along this dimension with papillae change and shrinking, both of which loaded positively. Papillae change was again interpreted as an indicator of arousal, as this behavior has been associated with alerting or arousal measures in $O$. vulgaris previously (Boyle, 1983). Mather and Anderson (1993) also described avoidance in adult $O$. rubescens; thus, this trait may be important across the genus. One of the funiamental axes of behavioral variation in vertebrates is the shy-bold continuum (Wilson et al., 1993). Shy individuals react to unfamiliar situations by retreating or becoming quiet and vigilant, whereas bold individuals act normally or actively approach the stimulus in the same situations. Controlled, quantitative experiments are needed to test whether avoidance for $O$. rubescens as well as avoidance/disinterest for $O$. bimaculoides may be a cephalopod version of this shy-bold continuum.

Behaviors that could be interpreted as indicators of arousal (color changes, papillae change, and respiratory change) loaded on three out of four dimensions in this study, suggesting that at least some sort of arousal contributes to each. It may be that these behaviors indicate different types of arousal in octopuses, similar to postulated arousal systems in humans (A. H. Buss \& Plomin, 1984). No attempts were made here to distinguish between behavioral, autonomic, or brain arousal.

Received May 8, 2000

Revision received May 9, 2001

Accepted May 13, 2001 